Case Report

\title{
QUADRIPAERESIS - A RARE CASE OF EPITHELOID HAEMANGIOENDOTHELIOMA.
}

\author{
Deepak Hegde' ${ }^{1}$, Vikram Shetty², J. P. Shetty ${ }^{3}$, Sandeep Kini B. \\ ${ }^{1}$ Assistant Professor, ${ }^{234}$ \\ Department of Orthopaedics, K. S. Hegde M edical Academy, Nitte University, Deralkatte, \\ Mangalore - 575 018, India.
}

Correspondence:

Deepak Hegde

Department of Orthopaedics, K. S. Hegde M edical Academy, Nitte University, Deralkatte M angalore - 575 018, India.

E-mail : deepakortho123@ rediffmail.com

\begin{abstract}
:
A $62 \mathrm{yr}$ old male presented with complaints of neck pain associated with weakness of both upper and lower limbs for 2 months.Weakness began with upper limb progressing to involve the lower limbs.

X-ray cervical spine showed C7 vertebral collapse with decreased joint spaces.M RI scan showed compression collapse of C7 vertebral body, thecal sac narrowing $\&$ cord changes at this level.C7 corpectomy and biopsy with anterior fusion with bone graft and instrumentation was performed revealing mass around $\mathrm{C} 7$ vertebra. Histology revealed fragments of cartilage, bone, \& vascular tumorcomposed of well formed vessels lined by cuboidal to hobnail endothelium. Focal areas showed lymphocytic infiltration and occasional benign giant cells suggestive of haemangioendothelioma. The purpose is to present a rare tumour occurring at an unusual site presenting as cervical myelopathy.
\end{abstract}

Keywords : Quadriparesis, Haemangioendothelioma.

\section{Introduction:}

Haemangioendothelioma

The term represents a wide spectrum of vascular neoplasms.

\section{Types -}

1. Epitheloid hemangioendothelioma

2. Malignant haemangiosarcoma

Epitheloid hemangioendothelioma

Synonyms: low grade anaplastic angiosarcoma, cellular hemangioma, histiocytoid hemangioma angioendothelioma. They have well defined vascular channels. Tumor cells are plump \& often cuboidal thus resembling epithelial cells.Occur in the calvarium, spine, femur, tibia and feet of adults during the second or third decade.Occurrence of this

Access this article online Quick Response Code

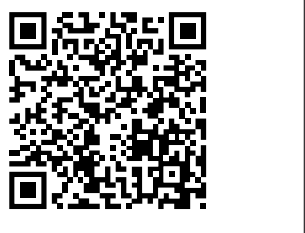
tumour in cervical spine is quite rare with best of our knowledge is $4^{\text {th }}$ such case.

\section{Case Report:}

62 yr old male presented to out patient department on 26/12/2007 with complains of neck pain associated with weakness of both upper and lower limbs for 2 months. Pain was insidious in onset, gradually progressive, radiating to upper limbs.

Began with upper limb progressing to involve the lower limbs. Required support for mobility since then.For past 1 week has not been able to ambulate.

No history of any trauma, fever, any bowel $\&$ bladder involvement.known hypertensive on irregular treatment.Had history of cough with expectorations for past 6 yrs associated with sputum production without haemoptysis.Clinically poorly built \& nourished with pallor.Cervical spine- lordotic cervical spine.Tenderness of C6 C7 spinous processes with paraspinal spasms.Range of movements- painful \& restricted.spasticity of both upper limbs with wasting .power of 4/5 below C7 level. Reflexes exaggerated with intact sensations and pulsations. Babinski reflex-Extensor response.

\section{Discussion :}

The term represents a wide spectrum of vascular neoplasms.

Typesare 

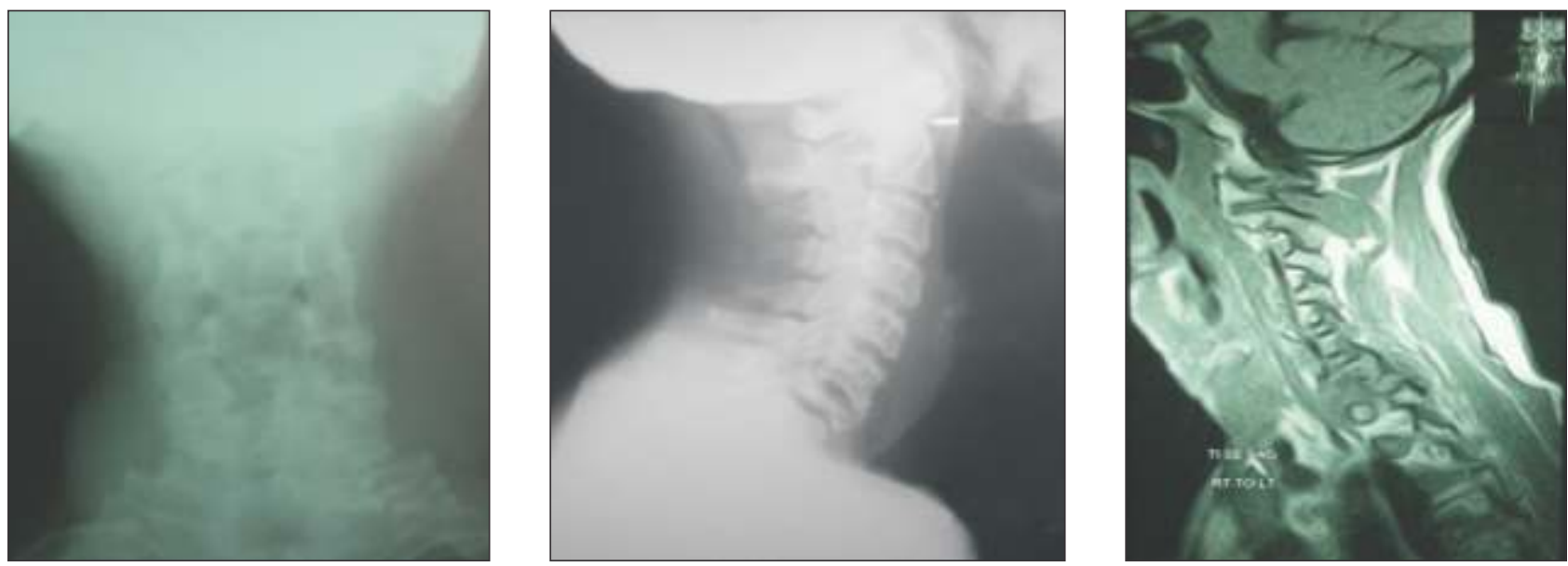

X-ray cervical spine showed C7 vertebral collapse with decreased joint spaces.M RI scan showed compression collapse of C7 vertebral body, thecal sac narrowing $\&$ cord changes at thislevel.
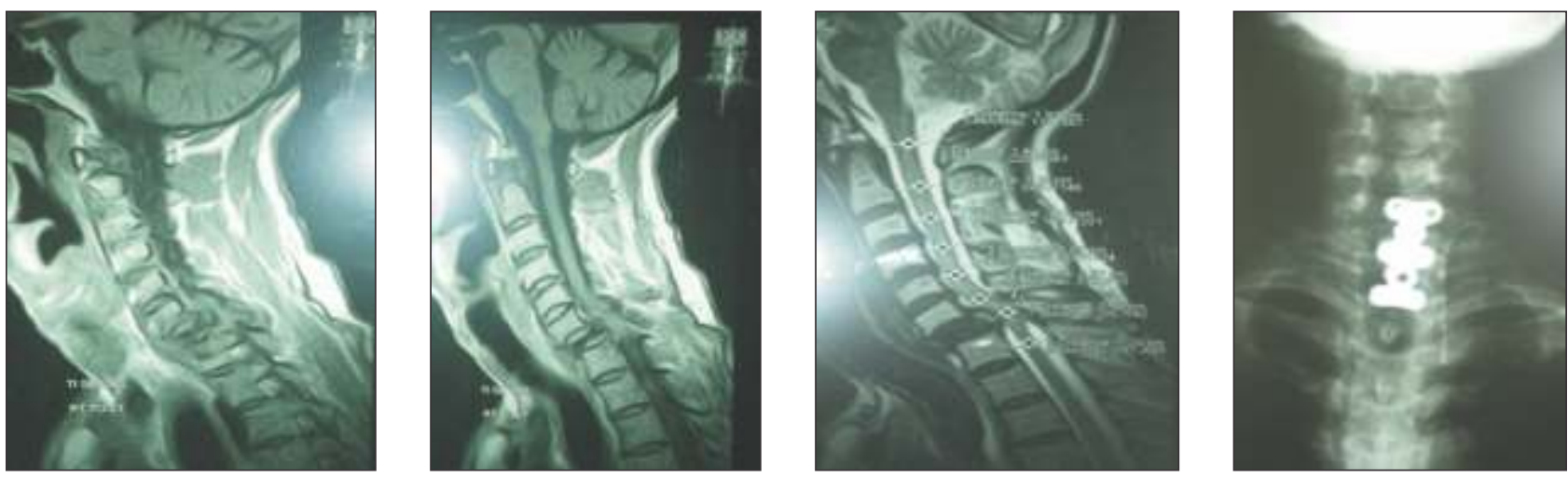

Secondaries, tuberculosis were thought of clinically. USG abdomen was normal, routine haemogram was normal apart from ESR being $26 \mathrm{~mm} / \mathrm{hr}$. Sputum for AFB - negative,PSA - normal.C7 corpectomy and biopsy with anterior fusion with bone graft and instrumentation was performed revealing mass around C7 vertebra. Histology revealed fragments of cartilage, bone, \& vascular tumor-composed of well formed vessels lined by cuboidal to hobnail

endothelium. Focal areas showed lymphocytic infiltration and occasional benign giant cells suggestive of haemangioendothelioma.

Postoperatively his vitals were stable, his pain had reduced motor deficits persisted with tingling numbness of fingers and toes. Short course of steroid was started on the second post op day. Patient was mobilized with walker on 3rd postoperative day. Was discharged with hard cervical collar.
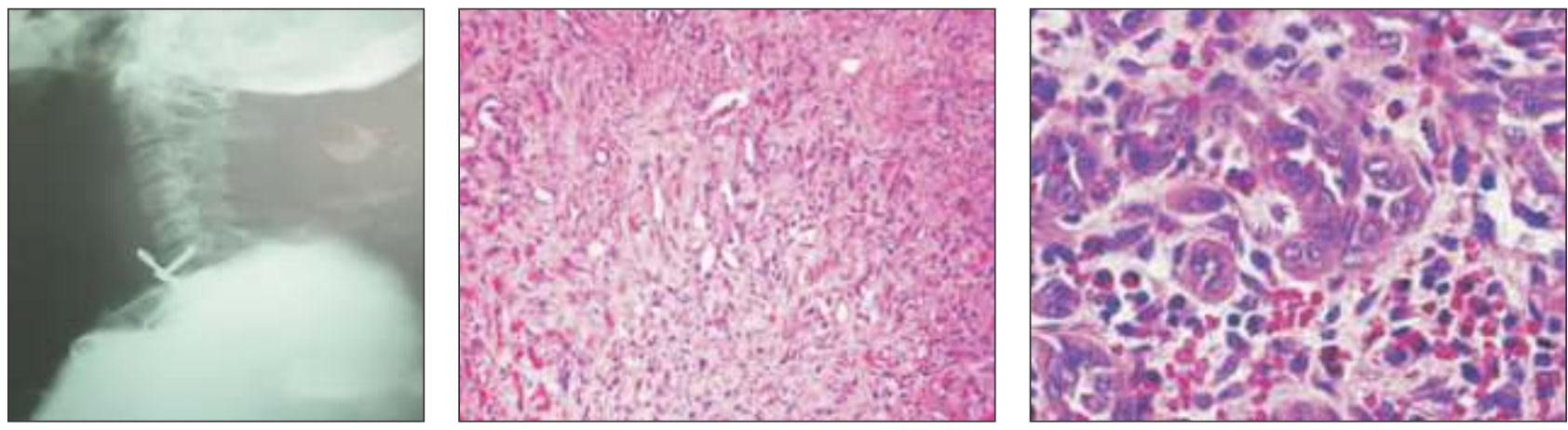

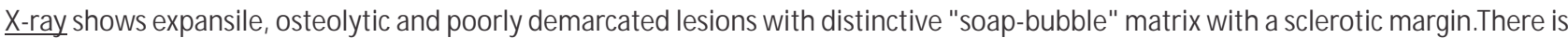
no periosteal reaction. Aggressive lesions-have ill defined margins and loss of trabeculae

Treatment: Grade the lesion. Benign- curettage or wide resection. The role of radiation and chemotherapy is controversial.If M alignant - wide excision with additional radiotherapy/chemotherapy.

Prognosis : Epithelioid hemangioendotheliomas may metastasize to bone and lung.Prognosis in these rare instances has been variable. 
1) Epitheloid hemangioendothelioma

2) Malignant haemangiosarcoma Synonyms are low grade anaplastic angiosarcoma,cellular hemangioma, histiocytoid hemangioma, angioendothelioma.

Epitheloid hemangioendothelioma has well defined

\section{References:}

1. Epithelioid Hemangioendothelioma of the Spine Presenting as Cervical Myelopathy: Case Report. Neurosurgery. 48(5):1166-1169, May 2001. Brennan, Jeffrey W. M .B.B.S.; M idha, Rajiv M .D.; Ang, LeeCyn M .D.; Perez-Ordonez, Bayardo M .D.

2. M C Casey, FFR, RCSI1, C Lim, FRCSI2 and M C Hickey, FFR, RCSI1. "An unusual cause of neck pain" British Journal of Radiology (2004) 77, 539-540

3. Boutin RD, Spaeth HJ, Mangalik A, Sell JJ. "Epithelioid hemangioendothelioma of bone." Skeletal Radiol. 1996 May;25(4):391-5.

4. Aquilina K, Lim C, Kamel MH, Marks CJ, O'Sullivan M G, Keohane C. "Epithelioid hemangioendothelioma of the spine. Report of two cases." J Neurosurg Spine. 2005 Nov;3(5):393-9

5. Aflatoon K, Staals E, Bertoni F, Bacchini P, Donati D, Fabbri N, Boriani S, Frassica FJ. "Hemangioendothelioma of the spine." Clin Orthop Relat Res. 2004 Jan;(418):191-7 Paul r. Sweterlitsch, Joseph S. Torg and Harvey Watts "Report-Malignant Hemangioendothelioma of the Cervical Spine: A Case" 1970;52:805-808.J Bone Joint Surg Am. vascular channels. The tumor cells are plump \& often cuboidal thus resembling epithelial cells.Occur in the calvarium, spine, femur, tibia and feet of adults during the second or third decade. 